\title{
Graduates' Voices: The Link Between University Graduates' Study and Job Experiences in East Africa
}

\author{
Omar Badiru Egesah \\ Associate Professor and Researcher, \\ Department of Anthropology, Moi University Kenya
}

\begin{abstract}
Studies on what programmes graduates studied while at the University, and how this ties in with employment; "Graduate tracer studies", have now spread worldwide. Such studies help inform and revitalize university programmes thus; they improve quality of higher education and learning since they provide important feedback results for use. In addition, this paper argues that graduate tracer studies also help to analyse how competencies acquired by the graduates during their university study relate to their jobs, and how such can help in understanding of the relevance of university programmes to the job market. Basically, we attempt to answer if and how university training produces competencies applied at work, or if there is a mismatch between training and work? The paper is discussed within the context of two connecting variables; study outcomes at university and the job situation. The paper answers two research questions thus; how is the graduates' transition to the labour market? and, what competencies are utilised by graduates at work? From a graduate tracer study conducted at Moi University and results analysed from 10 graduate tracer studies done in East Africa, we argue that graduates offer feedback that universities can intrinsically use to improve study programmes including curricula, service and administration, but they importantly, provide results that link study to work environments. There is a strong relationship between the field of study undertaken by graduates and their work. Graduates from Moi University and from East African Universities reported robust competencies acquired from their studies that are important for work. The paper concludes that graduates obtain from university studies, essential competencies that are relevant for work on the job market. The paper informs the East African higher education landscape about how graduate tracer study results are useful, and in specific terms, how universities in the region are training graduates for relevant competencies they use on the job market.
\end{abstract}

Keywords: Graduate Tracer Studies, UNITRACE, Competencies, Employment and Work.

DOI: $10.7176 / \mathrm{JEP} / 10-18-12$

Publication date: June $30^{\text {th }} 2019$

\section{Introduction}

Graduate tracer studies have spread worldwide in recent years. These studies focus on what programmes graduates studied while at the University, and how this ties in with their employment and work (Schomburg 2003). Graduate tracer studies are the best ever tool to show in recent times, how what universities train their students in, is relevant for the work they perform after graduation. There is a strong relationship between the field of study for graduates and the area of work (Teichler 2000; DeSeCo 2003; Gonczi 2003). As such, graduate tracer studies engage rigorous research undertaking to collect data on study and employment situation of the most recent graduates, in order to obtain indicators for their professional performance (Ramos 2006). Because of this, in the recent past, graduate tracer studies have been spurring greater employer interest, especially in European countries and the paper is hopeful too, sooner or later in East Africa. Universities worldwide strive to embrace market demands for their graduates for example, demonstrating propensity for participation in, and investigation of innovation and technological development mirrored on the job market (ibid). Graduate tracer studies are relentlessly becoming an exhilarating instrument by which extrinsic employer interests are fronted by universities.

UNITRACE is a contemporary worldwide programmatic concept that means university graduate tracer studies. It involves identification and follow-up of graduates from institutions of higher learning (HEIs), to learn from them about their experiences while at the university, and also to learn about their experiences in employment, after graduating. If universities wish to improve their teaching and training of graduates, the best precedence should be to learn from their own graduates. After all, graduates hold the most recent real experiences. Furthermore, universities should set comparative standards to be at par with other universities at both the national and international levels through comparable graduate tracer studies (Schomburg 2003). The importance of graduate tracer studies therefore is to incorporate improvements into the institutional effectiveness, by collecting and analysing information on graduates' professional and personal experiences. For example, such studies are used to collect data on the employment situation of the most recent graduates, in order to obtain indicators for their professional performance (Teichler 1998, Schomburg 2003, Wahome, Egesah \& Wanyama 2015). They can therefore, be used to contribute to causal explanations of the relevance of the study conditions and services provided by higher education institutions and graduates' performance in the labour market 
(Herrmann 2010, Teichler 2011, Schomburg \& Teichler 2011). In addition, such studies can help inform and revitalise university programmes through feedback obtained from graduate responses. They can help higher education bodies improve education and learning in such institutions, and in countries of their charge. According to OECD (1999), Ulrich Teichler (2003) and Harald Schomburg (2003), graduate tracer studies have potential for policy and practice change that can shape both academics and development. As aforementioned, they can also help tailor university programmes to the job market thus, a realisation of the relevance of university study programmes to work.

Graduate tracer studies (GTS) were systematically, introduced at Moi University Kenya and in East Africa, under the German framework of the graduate tracer study programme; UNITRACE. Two nominees to the UNITRACE programme undertook a graduate tracer study at Moi University (MUTRACE), targeting the 2009 cohort of graduates, and in this paper, methodological lessons and selected study-work results of the survey are presented. The topic of graduates transiting to the job marked is internationally discoursed under the EXLIMA (Link and Match forum for graduate tracer studies), but also in this paper. Precursor though to this link between theory and prcatice, we must appreciate the methodological processes and thematic issues in graduate tracer studies. Unique to graduate tracer surveys, are the systematic but arduous methodological exigencies (Schomburg 1995, 2003; Egesah et al. 2012). Globally, renown and enduring graduate tracer studies such as KOAB, REFLEX, INDOTRACE, DEHEMS and CHEERS always emphasize important steps in the methodology of conducting GTS, including; the preparation and interview phase; professional standard domain approach; domestic national and university level domains, and; dissemination and utilisation of GTS results. Basically, this speaks about embedded steps of GTS research and results.

In addition, this paper also reports from the most recent experiences following up on UNITRACE; the experience under which the author and colleagues trained 20 university staff from 10 universities in East Africa on graduate tracer study course (UNTRACE 2.0). UNITRACE 2.0 took place between 2016 and 2017, and one of its memorable outcomes besides GTS capacity building, is a graduate tracer study training manual (Stammen Karl-Heinz 2017). Stammen (2017) outlays the steps we follow to conduct successful graduate tracer study surveys, within the East African Universities framework, using the UNITRACE 2.0 model.

Tapping from both UNITRACE and UNITRACE 2.0 experiences, the author argues that there is a link between the programmes that graduates undertake while at the university and the work they engage in on the job market. It is prudent at this level, to appreciate that soundly developed project action plans (PAPs) are vital to methodologically steer GTS processes to desirable results. The essential connection between GTS methodology, planning and results has also been studied by various GTS researchers including (Grooves 1989; Dillman 2008; Heidemann 2010; Flotcher 2010; Herrmann 2010). Notwithstanding, of paramount importance to graduate tracer surveys, are the results and their utilisation (Schomburg 2003). Tracer survey results can be utilised in complex dichotomous platforms depending on need. For example, we can use GTS results based on intra-university needs, such as for improvement of study conditions and programmes, as well as, for extrinsic needs including determination of competencies desired on the job market, on the other hand (Burton \& Guy 1992; Teichler 2002).

This paper is developed from results of two graduate tracer study projects including UNITRACE GTS project, conducted in 2011 at Moi University from graduates in seven faculties. In addition, the paper is generated from analysis of project action plans and selected results of the UNITRACE 2.0 GTS project. Results from both UNITRACE GTS and UNITRCAE 2.0 GTS, are shared in this paper. The broad objective of this paper is therefore to analyse how competencies obtained during university degree study are utilised by graduates at work. The paper thus, relies on results collated from eleven universities from East Africa. The paper presents heuristic graduate tracer study results concerning methodological approaches in conducting GTS, transition of graduates to the labour market and about application of study competencies at work.

\subsection{Specific objectives}

The objectives of this paper are to:

1. Explain factors considered in graduates' transition from study to the labour market.

2. Relate study competencies to employment and work.

\section{Methodology}

UNITRACE started in 2010 with the training of two researchers from Moi University in graduate tracer surveys in a series of three consecutive, but iterative workshops. First, was graduate survey preparation in 2010, encapsulating exposure to relevant theories, survey designs, and development of a comprehensive accurate graduate address data bank. Organisation and conduct of the actual survey followed between April-June 2011. Data were analysed in SPSS and QTAFI in 2011-2012 and two papers written with results shared widely at Moi University, and extrinsically in conferences and workshops. Researchers started by sensitization, seeking goodwill and obtaining authoritative support from the Moi University management and administration to enable them carry out the survey. This was important because, it was the first time a graduate tracer study was being 
conducted at Moi University. To successfully conduct a GTS, one needs to develop and rely on an accurate address data bank. Data were collected using a standard questionnaire, by email attachment, and reinforced through telephone call reminders. The questionnaire items were classified into five sections; socio-biographic characteristics of respondents; study conditions and provisions; job search and transition to work; employment and work; work and competencies. It is argued that tracer studies with as low as $30-40 \%$ response rates are often regarded as credible, given that GTS surveys often use a self-administered questionnaire and also owing to the fact that in tracer surveys, there is often high propensity not to trace the graduates after they leave the university (Schomburg 2007, Ramos 2006). The study returned 41\% response rate from a population of 873 , from which an address data bank of 722 was drawn. From a target population of 470, data were collected from a sample of 193 graduates, in three months.

Data obtained were entered and cleaned as well as checked for consistency and accuracy in an Ms Excel data sheet. Consequently, data were transposed into SPSS 17, again checked for accuracy and completeness, before descriptive analyses were carried out. Key variables to the paper; Socio-biographic characteristics, transition to the labour_market and study competency, were analysed. Quantitative descriptive findings are presented in simple percentages and measures of central tendency, using graphs, tables and charts. To appraise on the three variables of interest, the researcher analysed results and project action plans (PAPs) for graduate tracer studies from ten (10) public and private universities in East Africa (Kenya-5, Tanzania-3, and Uganda-2). These results were initially obtained from 10 GTS studies conducted by trainees of the UNITRACE 2.0 course, in the year 2016. Universities surveyed under UNITRACE 2.0 were, Kenya: Moi University, Laikipia University, Technical University, Catholic University of East Africa, and Tangaza University College. Tanzania: Aga Khan University; University of Dar es Salaam and State University of Zanzibar. Uganda: Islamic University in Uganda and Uganda Christian University. Absolute samples for UNITRACE 2.0 GTS were 1443 graduates. Collated results on study competencies and work, together with results of UNITACE- Moi University, are presented and shared in this paper.

\section{Results}

Broadly speaking, the paper argues that graduate tracer studies are gaining global recognition in their contribution to improvement of higher education, and also that GTS results are useful in interpreting the link between study programmes and employment work. Results from both the Moi University graduate tracer study, and from GTS in a conglomerate of 10 East African Universities are presented here.

First, we start with results from the Moi University study. From the Moi University study, 55\% of graduates were males, while $45 \%$ were females. In Kenya, there are a slightly higher number of males that attend education than females, and this percentage above is indicative of this fact. Most graduates $(67 \%)$ were aged between 25 27 years by the time the study was conducted (mean=27). All the graduates had degrees from various faculties of Moi University, having graduated in the study fields of law, arts and social sciences, engineering, information sciences and ICT, medicine, nursing and environmental health. Although graduates offered information and feedback that universities can use to improve study programmes, this paper dwells on how study programmes relate relevantly to employment and work.

\subsection{Study Environment}

Additional education and training during study

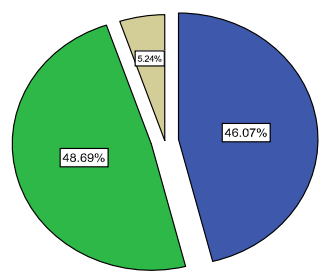

In addition to their fields of degree study, graduates undertook additional courses to expand their study scope, and to help in their transition to work. Additional courses commonly taken were computer studies and ICT, accounting, secretarial administrative courses, project management, monitoring and evaluation, disaster management, environmental studies, leadership, impact assessment, entrepreneurship, creative arts and report writing. Skills oriented courses such as driving, first aid, fire fighting, HIV peer education and counseling, and languages, were also taken. To quote one graduate, such additional courses "...gave a sense of motivation, actualization and satisfaction”.

Lectures were a mode of learning very highly emphasised at Moi University (78\%). Emphasis was also put on student's participation in research (53\%), internship (57\%), practical exercise, field courses and practicum $(62 \%)$ and discussions (59\%). Rating for conducting research, dissertation and research paper work were also well placed $(33 \%)$. The study utilised a rating scale of $1=$ very high $-5=$ very low, for ordinal scale variables. Fieldwork was averagely emphasised at Moi University (median 3, on a rating scale of 1-5). However, 30\% 
indicated that demonstrations were not emphasised at Moi University. Community services and outreach were rated as low (median and mode 4). Overall, learning conditions and facilities at Moi University were rated as average by $37 \%$. Despite this, Moi University graduates $(92 \%)$ completed their study in the standard period of time.

\subsection{Graduates transition to the labour market}

Moi University graduates started searching for jobs 5 months before graduation; however, they continued to search for employment 2 months of post-graduation, before they were eventually employed. Most graduates (54\%) relied on advertisements in newspapers, magazines and fliers to search for their first job after graduation. Half of the graduates checked through the internet, online, mailing lists for advertisements and only $10 \%$ had established an e-network for searching for their first job. Engineering graduates were contacted by companies for their first job, unlike other graduates. Negligible numbers of graduates used the career office, job fairs, and the government and commercial agencies, to search jobs. Only $6 \%$ of the graduates established their own private businesses. Interestingly, $32 \%$ of graduates searched for their first jobs through parents, relatives and friends, and $21 \%$ of the graduates searched for their first jobs through work placement, internship and attachment. Before they got their first job, graduates contacted at least 10 (mode) institutions to seek employment.

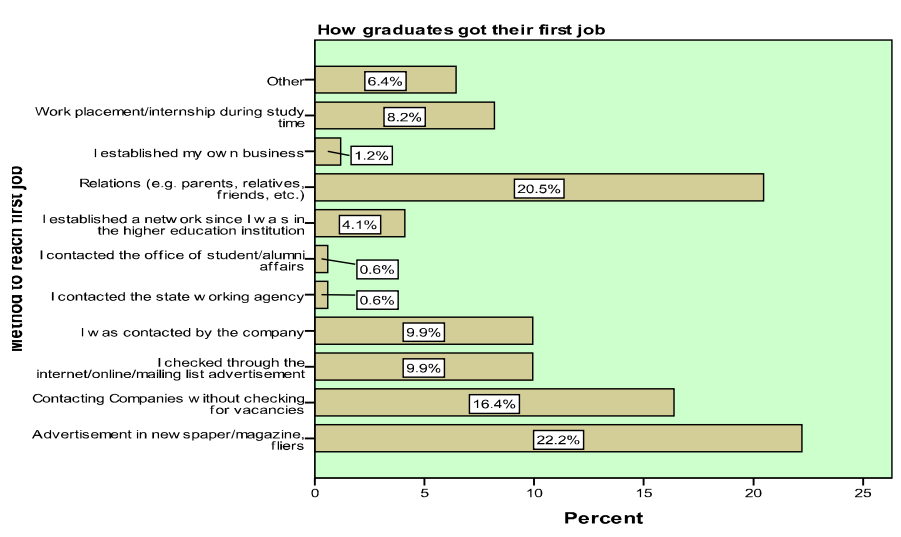

Most graduates obtained their first jobs through advertisements in newspapers $(22 \%)$ and through parents, relatives and friends $(21 \%)$. Avenues such as government, work agencies, and students alumni were the least used to search jobs. Graduates with degrees in medicine were directly employed by the Ministry of Health, Kenya.

\subsection{Important considerations for employer in recruiting graduates}

Nearly half of the graduates $(46 \%)$ felt that the study programmes was important for the employer in recruiting them for their first employment. Grades attained, were not seen as important criterion for consideration for employment (64\%), meaning it did not matter if you passed so highly or not, to be employed. Interestingly too, $65 \%$ considered reputation of the University as important for the employer in recruiting. Graduates were expected to be already computer literate at the time they searched jobs.

\subsection{Job selection criteria}

Graduates considered mostly, the salary amount, in selecting their first job offer ( $42 \%)$. Salary thus, was an important consideration regardless of the nature of the job. In

Most considered aspects in selecting first job-offer

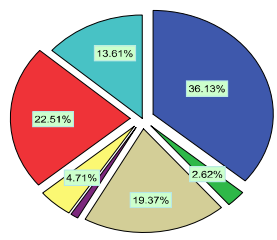
addition, $22 \%$ of the graduates preferred challenging jobs. Surprisingly, graduates did not consider benefits such as housing, transportation, overtime and proximity to their residence, when selecting jobs.

$79 \%$ of Moi University graduates were employed by the time of the survey but $21 \%$ were not employed one year after graduation.

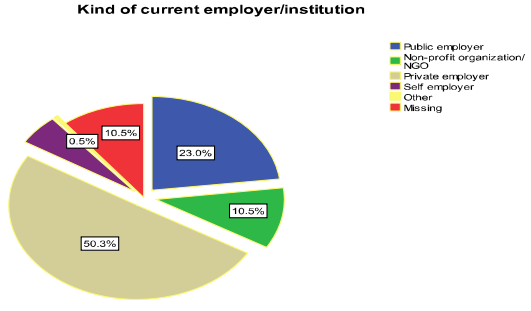


On the other hand, $50 \%$ of Moi graduates worked for the private employer. Surprisingly, the public employer had only $23 \%$ and NGO sector had $11 \%$, while interestingly, $6 \%$ were self-employment. Averagely, graduates had worked for 2 employers in one year's time.

\subsection{Occupational distribution and salary earnings}

Graduates were distributed in various occupations. Research $12 \%$, legal work $10 \%$, mechanical and technical work $8 \%$, ICT 7\%, writing, publishing and media 5\%, business, marketing and commerce 5\%, administrative assignments $5 \%$ and in patients' treatment and management $5 \%$.

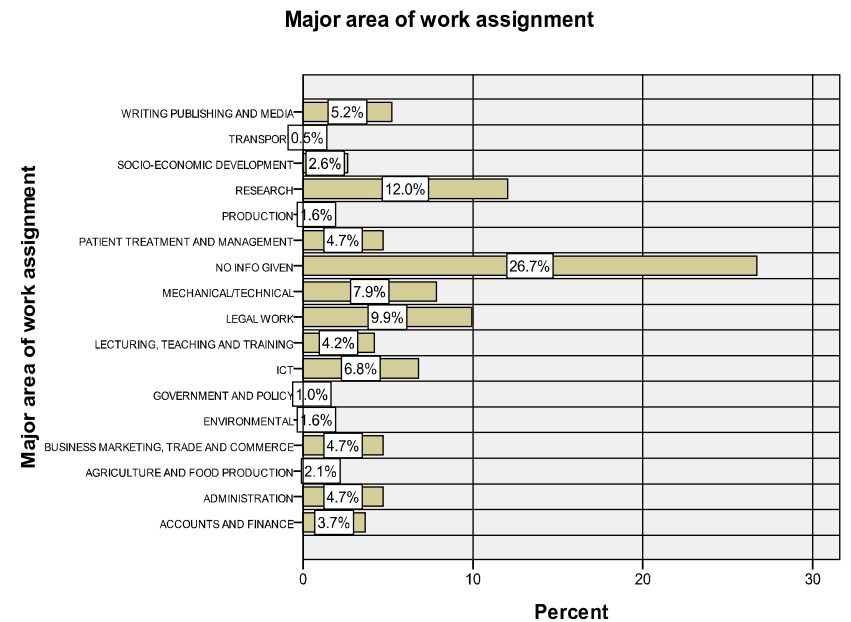

Per week, graduates worked 34 hours (mean=34.45). Maximum hours in a week reported were 168 with $28 \%$ working on average 8 hours per day. Approximate monthly gross income from the main job excluding overtime and extra hours for the graduates was, Ksh. 41,870 per month, $=511 \$$. The lowest earned only Ksh. $2,000=24 \$$, while the highest earned Ksh. $250,000=3049 \$$. To supplement from side jobs, referred to in Kenya as "side hustles", graduates earned approximately Ksh. $21,000=\$ 256$.

\subsection{Study competencies and their application and relevance to work}

Despite the aforementioned, there is a strong link between what study programme the graduate underwent and

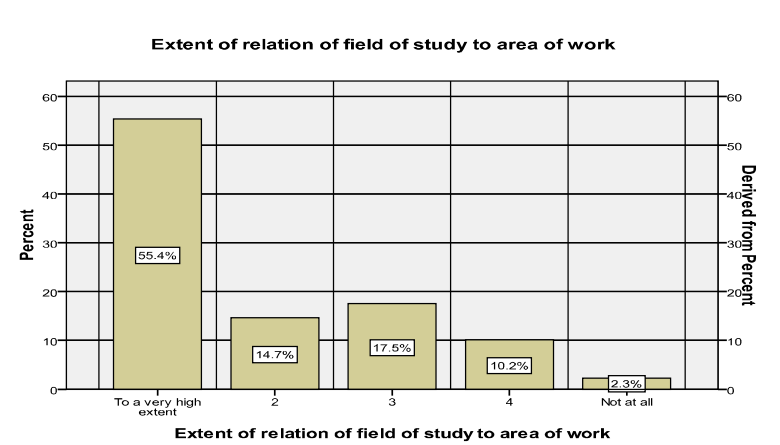
the form of employment they engage in. Relationship between the field of study for graduates and the area of work was rated as (very) high $(70 \%$, median and mode $=1)$. Teichler $(2000)$ argued in approval, of this link, in a study of universities in several European countries. For our case, university degree study programmes were seen as basis for starting work $(68 \%)$. Similarly, these programmes formed the basis for further learning at work $(77 \%)$. Study programmes also formed foundation for performing current work tasks $(73 \%)$ and potential for future careers $(83 \%)$, including personal development $(88 \%)$. Therefore, the

degree study programmes were very essential in the careers of graduates.

Graduates who were surveyed at Moi University, were in addition, asked to what extent they had specific competencies by the time of graduation, and to what extent the University had contributed to these competencies. Table 1 below, gives a summary of the competency ratings $(1=$ to a very high extent, while $5=$ not at all). 
Table 1: Study competencies and utilisation at work $(1=$ Very high extent, $5=$ Not at all $)$

\begin{tabular}{|c|c|c|c|}
\hline Competency & $\begin{array}{l}\text { Competencies at } \\
\text { graduation time }\end{array}$ & $\begin{array}{l}\text { University contribution } \\
\text { to competencies }\end{array}$ & $\begin{array}{l}\text { Utilization of } \\
\text { competence at work }\end{array}$ \\
\hline Knowledge of discipline* & $2=73 \%$ & $1=81 \%$ & $1=77 \%$ \\
\hline Knowledge of other fields** & $3=42 \%$ & $3=26 \%$ & $2=63 \%$ \\
\hline General knowledge & $2=78 \%$ & $2=50 \%$ & $2=52 \%$ \\
\hline Internet skills & $1=81 \%$ & $5=42 \%$ & $1=77 \%$ \\
\hline Computer skills & $1=82 \%$ & $3=23 \%$ & $1=80 \%$ \\
\hline Critical thinking & $1=80 \%$ & $2=72 \%$ & $1=89 \%$ \\
\hline Research skills & $2=63 \%$ & $1=80 \%$ & $1=82 \%$ \\
\hline Learning ability & $1=85 \%$ & $2=73 \%$ & $1=88 \%$ \\
\hline Communication skills & $2=78 \%$ & $2=74 \%$ & $1=94 \%$ \\
\hline Working under pressure & $2=70 \%$ & $2=78 \%$ & $1=88 \%$ \\
\hline Time management & $2=75 \%$ & $2=61 \%$ & $1=89 \%$ \\
\hline Working independently & $1=80 \%$ & $2=66 \%$ & $1=88 \%$ \\
\hline Team work ability & $1=80 \%$ & $2=76 \%$ & $1=88 \%$ \\
\hline Problem-solving ability & $2=77 \%$ & $2=65 \%$ & $1=90 \%$ \\
\hline Negotiation & $2=59 \%$ & $2=26 \%$ & $2=75 \%$ \\
\hline Analytical ability & $2=67 \%$ & $2=64 \%$ & $1=85 \%$ \\
\hline Tolerance & $2=72 \%$ & $2=60 \%$ & $1=82 \%$ \\
\hline Adaptability & $1=81 \%$ & $2=71 \%$ & $1=87 \%$ \\
\hline Loyalty and integrity & $1=85 \%$ & $2=58 \%$ & $1=82 \%$ \\
\hline Work with different people & $1=78 \%$ & $1=77 \%$ & $1=91 \%$ \\
\hline Leadership & $2=78 \%$ & $2=63 \%$ & $1=85 \%$ \\
\hline Responsibility & $1=81 \%$ & $2=65 \%$ & $1=90 \%$ \\
\hline Initiative & $2=75 \%$ & $2=64 \%$ & $1=88 \%$ \\
\hline Project management & $2=63 \%$ & $2=62 \%$ & $1=77 \%$ \\
\hline Able to present ideas \& info & $2=73 \%$ & $1=80 \%$ & $1=90 \%$ \\
\hline Able to write reports \& docs & $2=79 \%$ & $1=83 \%$ & $1=89 \%$ \\
\hline Able to continuously learn & $1=89 \%$ & $1=80 \%$ & $1=93 \%$ \\
\hline Averaged scores*** & $2=75 \%$ & $2=64 \%$ & $1=84 \%$ \\
\hline
\end{tabular}

The average*** of scores for all the 27 competencies researched, show that, graduates' competencies held at the time of graduation were highly rated $(2=75 \%)$. Training at Moi University highly contributed to these competencies $(2=64 \%)$. Generally speaking, graduates were highly utilising these competencies at work $(1=$ 84\%). Competencies in the knowledge of the discipline* graduates studied, was highly important at all the three levels; gained at university $(73 \%)$; contributed by university $(81 \%)$ and; utilised at work (77\%). However, some competencies were not useful and were least achieved at the university, for example, knowledge of other disciplines**. This shows that Moi University graduates were more specialized in their fields and less diverse in knowledge outside their disciplines, and this could be a weakness in case application of broad and general knowledge outside discipline, is required for work.

Turning our focus to results of UNITRACE 2.0, data on the same competencies and work variables, were analysed in 2016, and collated for comparison purposes, from the 10 universities that carried out graduate tracer surveys within the UNITRACE 2.0 project. Researchers asked the respondents to show if the field of study influenced their employment, and true the fields of study, contributed to graduates being employed, (for all the 10 HEIs), as shown below: 


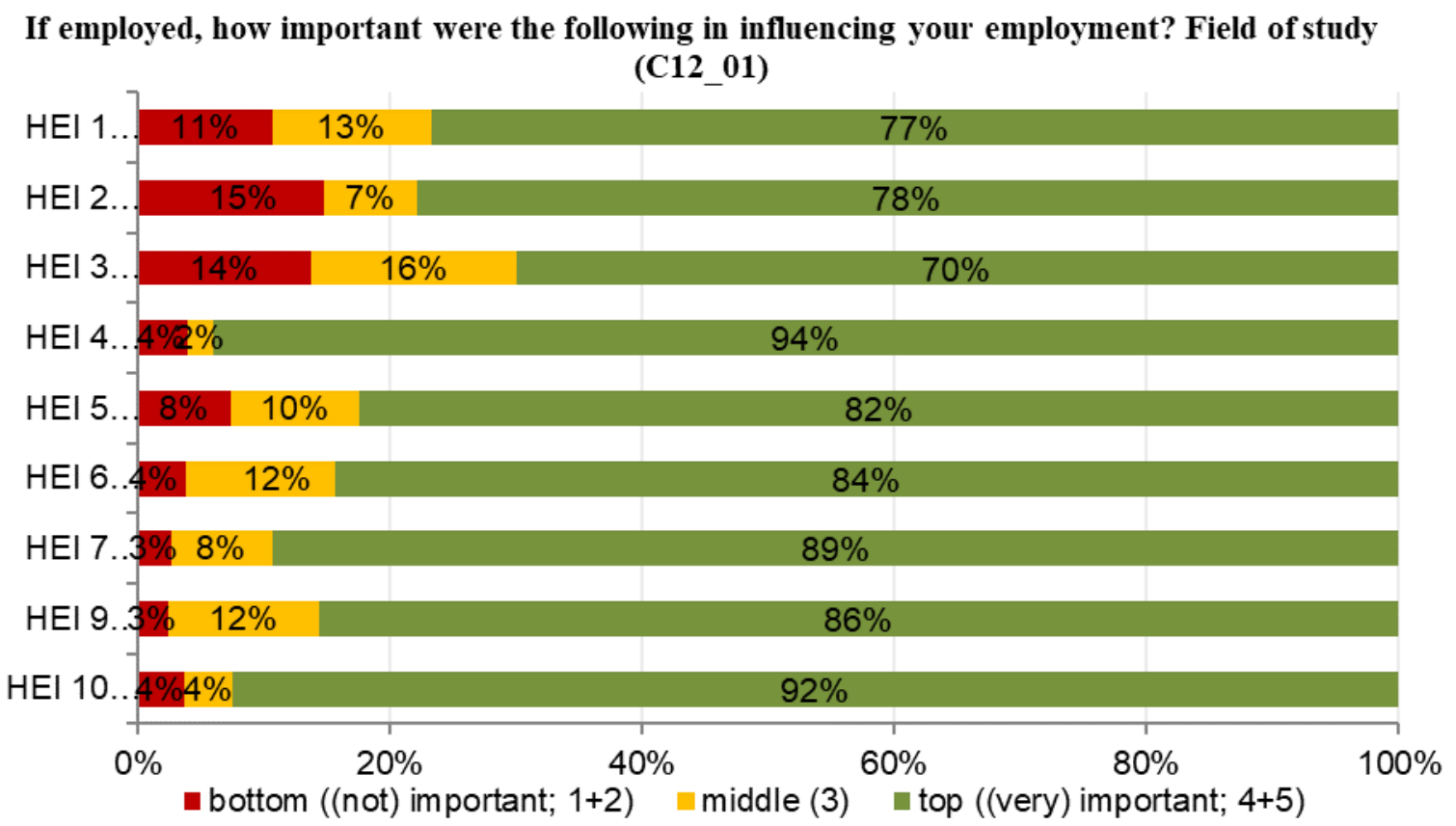

Researchers also asked graduates, how important the relevance of study programmes was in influencing the graduates' employment. Overwhelmingly so, the study programmes were relevant in influencing employment at all the 10 HEIs. This influence though was fairly less important for HEI number 3, as shown in the bar chart below $(20+21=41 \%)$ :

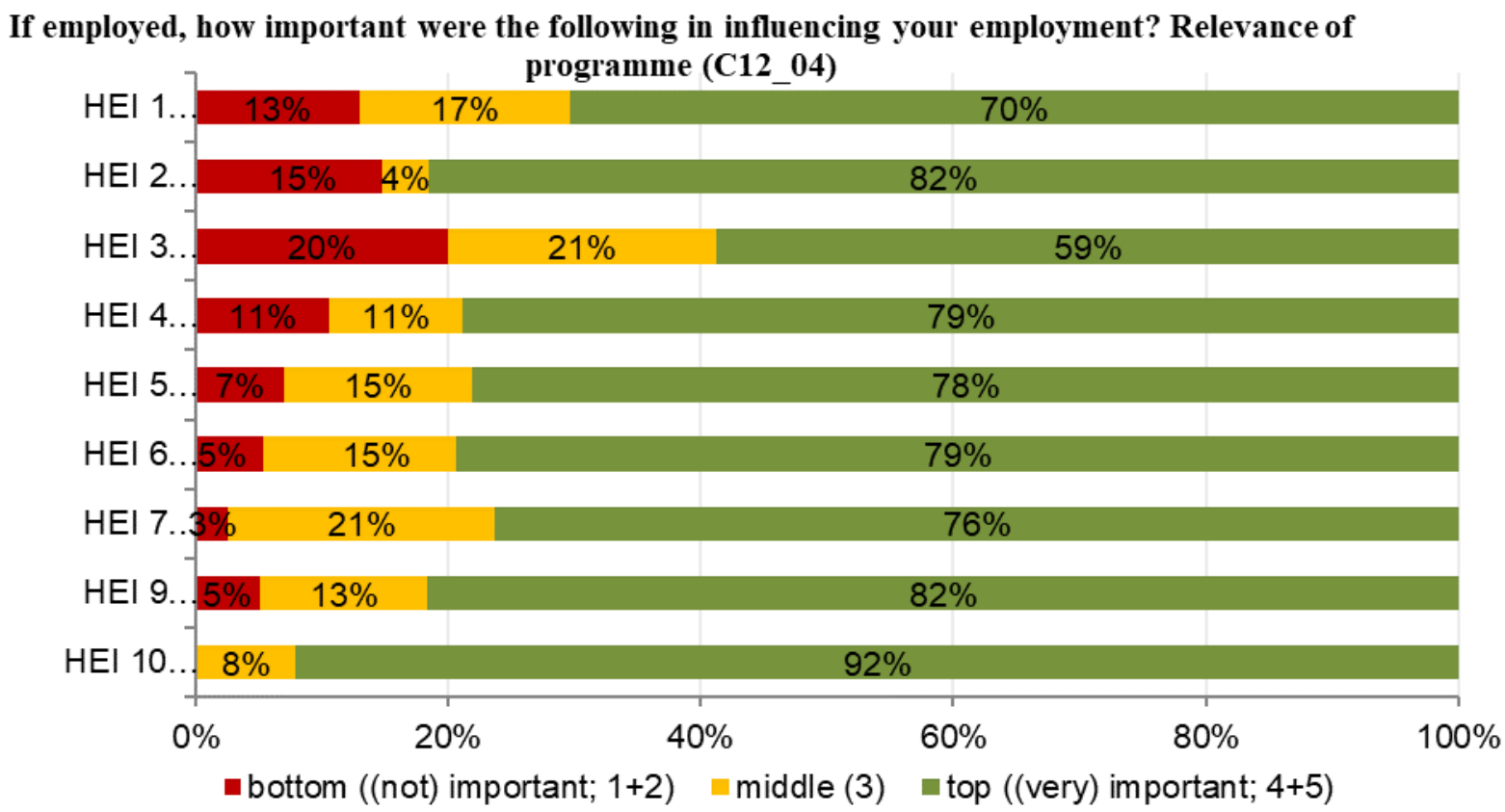

Finally, researchers asked graduates two questions; to what extent they had competencies in knowledge of their field of study (discipline of study), and; to what extent they were utilising the competencies, in their work. Each of the 9 HEIs presented in the bar chart below has two bars; the top bar shows the extent graduates had the competencies and the bottom bar for each HEI shows the extent to which graduates were utilising the competencies. As shown, graduates in all the 9 HEIs indicated a high extent of having competencies in knowledge of their field of study and correspondingly, a high extent in utilising the competencies in their work. However, in HEI-3, despite having the competencies (77\%), the graduates were least utilising the competencies in their work $(13+24=37 \%)$. But the opposite manifests for HEI-9, where there is low extent in competencies in 
knowledge in discipline, $(11+27=38 \%)$, although to a very high extent $(92 \%)$, they were using these competencies in their work.

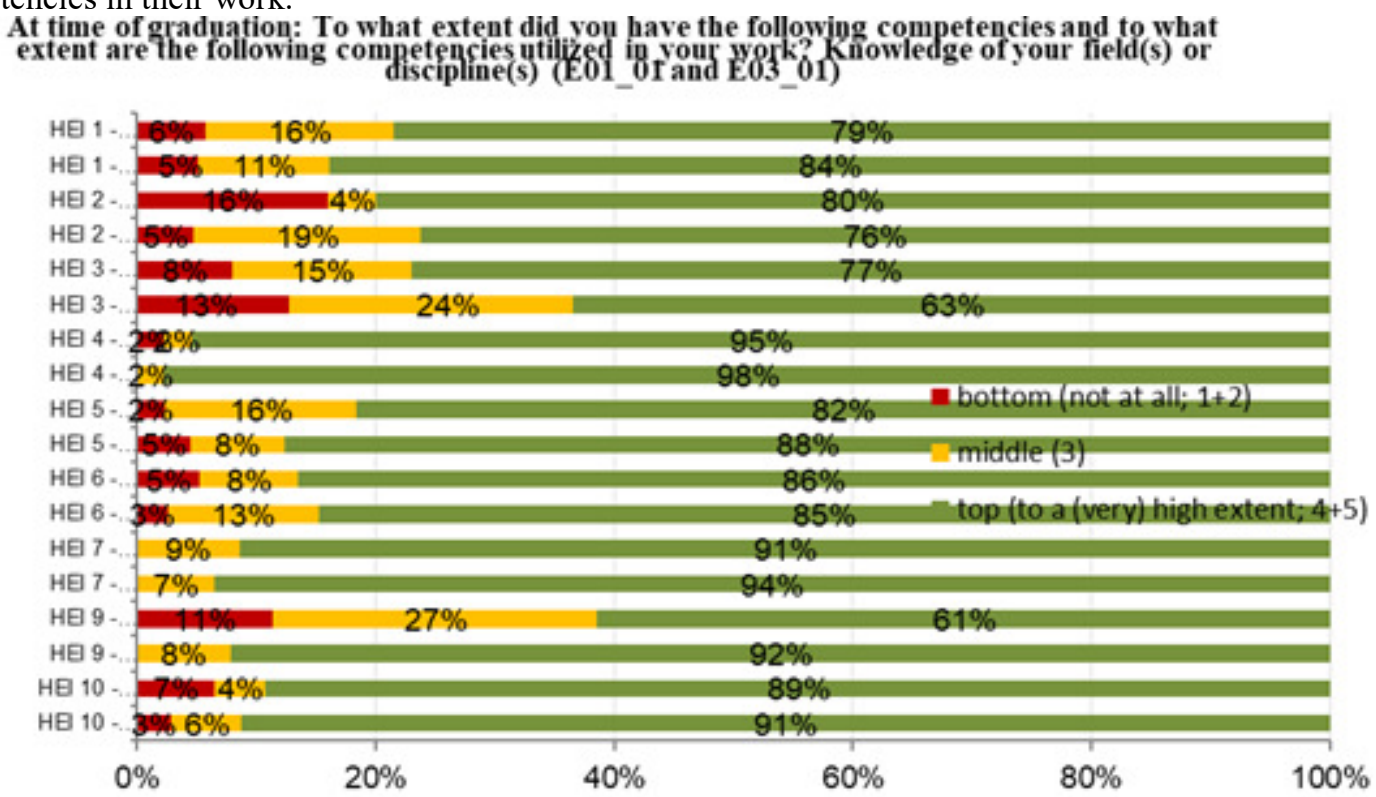

\section{Discussion}

This paper discusses results of the connection between graduates' fields of study and utilisation of competencies in the fields of study at work. The paper also explains important experiences of graduates' transition to the labour market, upon graduation. Before we discuss the results, it is important to point out that graduate tracer study results obtain from specific step by step methodological processes that are uniquely important to graduate tracer studies. According to Sanyal (1987), Ulrich Teichler (1999), Harald Schomburg (2003), Egesah et al., (2012) and lately, Karl-Heinz Stammen (2017), tracer study methodology, if designed with appropriate themes, strategies and appropriate designs, do often yield desirably utilisable results. This paper explores experiences of graduates in transition to the labour market, arguing how study programmes of graduates of Moi University and nine other universities in East Africa, offer competencies that graduates utilise in their work. Ulrich Teichler has repeatedly studied and proved beyond doubt, that there is a strong link between the field of study undertaken by graduates and the area of work (Teichler 1998, 1999, 2000, 2011), basing his studies on graduates from European universities. This paper adds voice to this fact, showing in the results section that profoundly, graduates gain competencies in their fields of study at their universities in East Africa, and that universities actually contribute immensely to building in graduates, these competencies. Importantly, graduates are using these discipline-based knowledge competencies in their work, on the East African job scene. For us, this demonstrates that what East African Universities are training graduates in, is relevant to the job market, contrary to what many skeptics in the employment sector in East Africa, have recently felt and expressed. More good news from this study, is that graduates in both public and private universities in the East African region, complete their studies on time without delaying at universities. Furthermore, graduates do not delay for a long time after graduation, before they are employed, although this trend could be changing, given the chronic unemployment situation in East Africa. Unemployment in Kenya for example, was 12.7\% in 2006, 40\% in 2011 and even beyond $40 \%$ in 2017 . We argue that if graduates complete their studies on time, they get employed without much delay and use their university knowledge competencies at work, it means, universities in the East African region are effectively training graduates. In East Africa, one of the main reasons why we train graduates is for them to get employment and offer knowledge competency based services at work. Although this could be happening, graduates themselves hold a different view. Contrary to our foregoing observation, graduates in East Africa, do not really consider service provision as the overriding factor why they train, but instead, they report in this study, that they train to get employment and as a result, earn a salary. Therefore, if the competencies graduates gain from universities only aid them to obtain an employment, to work, so that they ultimately earn a salary, planners of university education in East Africa need to re-orient graduates' mind sets to focus on application of competencies at work for development service provision. After all, results presented in this study show high relevance of study competencies to employment work. Graduates took some courses besides their field of degree study, while they were studying at the university, to prepare themselves for the workplace. This indicates how uncertain graduates can be over their work contributions in the future. This could also indicate that universities should holistically prepare graduates to diversify knowledge and competencies bases, besides 
offering the graduates with specialized knowledge competencies obtained from their respective degree of study disciplines. Our argument in this paper resonates with what Rychen and Salganik (2001) and Gonczi (2003) reported, that there is a profound link between competencies acquired during university study and that universities contribution to acquisition of these competencies by graduates and furthermore, graduates utilise the competencies during work.

\section{Conclusion}

Graduates in both public and private universities in East Africa obtain from university studies and experiences, essential competencies that are relevant for employment and which are also utilised in their work. Knowledge oriented competencies of graduates are applied in work situations to foster work performance but not merely to keep the graduates on a salary. Such competencies can be supplemented by skills acquired outside the degree field of study, to enhance suitability of graduates in their work. This paper discusses results that explain the link between university training and work in the East African higher education training and job market contexts.

\section{Recommendations}

i. In the East African context, university education is mostly undertaken as means to gain employment and earn a salary. We must flip around this perspective, so that the overriding goal should be universities training graduates to offer competency driven work services for development.

ii. For long, around East Africa, we have assumed that universities are ivory towers that do not train for the labour market. This is not true, as presented in this paper. Institutions of higher learning in East Africa can disapprove this fallacy, by carrying out more research that show how graduates from universities in the region perform their work, utilising competencies gained from university studies.

iii. Universities in East Africa should continually review their teaching-learning curricula to ensure they train in job market driven competencies. Universities should in addition, offer supplementary courses to degree fields of study, to enable graduates acquire along degree studies, critical competencies and skills needed at work.

\section{References}

Braun, M. (2011). DEHEMS- Network for the development of higher education management systems (DEHEMS). Kassel: INCHER-Kassel UNITRACE.

Burton, R. C. \& Guy, N. (1992). The encyclopedia of higher education. Oxford: Pergmon Press.

DeSeCo. (2003). Definition and Selection of Competencies: Theoretical and Conceptual Foundations. Retrieved from www.deseco.admin.ch

Dillman, D. A. (2008). Internet, mail and mixed-mode surveys: The tailored design method. New York: Willey.

Egesah, O. B., Wahome, M., Langat, E. K., \& Wishitemi. B. E. L. (2012). University graduate tracer studies (UNITRACE): Methodological lessons and utilization of selected results at Moi University, Kenya.

Journal of International Academic Research for Multidisciplinary, 2(8), 305-325.

Enders, J. \& Ulrich, T. (1997). A Victim of their own Success? Employment and working conditions of academic staff in comparative perspective. Higher Education, 34, 347-372.

OED. (2010). Experience and Job in Kenya. Retrieved from lnweb90.worldbank.org/oed/oeddoclib.nsf/.../\$file/198precis.pdf

Flotcher, C. (2010). Address data bank and website for the graduate survey. Kassel: INCHER-Kassel UNITRACE.

Gonczi, A. (2003). Teaching and Learning of the Key Competencies. In D. S. Rychen, L. H. Salganik \& M. E. McLaughlin (Eds.), Contributions to the Second DeSeCo Symposium (pp. 119-131). Neuchâtel: Swiss Federal Statistical Office.

Grooves, R. M. (1989). Surveys errors and survey costs. New York: Willey.

Heidemann, L. (2010). Introduction, preparation and conduct of tracer surveys; practical aspects of the project implementation. Kassel: INCHER-Kassel UNITRACE.

Herrmann, D., Dilger, B. \& Junghanns, M. (2010). Specialized questionnaires in graduate tracer studies; demand, development and back channeling results. Koln: University of Cologne.

Hoeper, B. (1993). Quality, relevance and efficiency in higher education in Africa. Report on the International Seminar in Harare, Zimbabwe. Bonn: Deutsche Stiftung für Internationale Entwicklung.

Kenya National Bureau of Statistics, Government of Kenya. (2010). Wage Employment by Sector 2005-2010. Nairobi: Government Printer.

Organization for Economic Co-operation and Development (OECD). (1999). Preparing youth for the $21^{\text {st }}$ century: Transition from education to the labour market. Proceedings of the Washington DC Conference, Washington DC.

Ramos, T. (2006). Graduate follow-up instruments and recommendations manual. Mexico: Instituto 
Technologico de Estudios Superiores de Monterrey.

Rychen, D. S. \& Salganik, L. H. (Eds.). (2001). Defining and selecting key competencies. Göttingen: Hogrefe \& Huber.

Rychen, D. S., \& Salganik, L. H. (Eds.). (2003). Key competencies for a successful life and a well-functioning society. Göttingen: Hogrefe \& Huber.

Sanyal, B. (1987). Higher education and employment: An international comparative analysis. London: The Falmer Press.

Schomburg, H. (1995). Standard instrument for graduate and employer surveys. Kassel: Eschborn and Kassel.

Schomburg, H. (2003). Handbook for graduate tracer studies. Centre for Research on Higher Education and Work, Kassel: University of Kassel, Germany.

Schomburg, H. (2007). The professional success of higher education graduates. European Journal of Education, 42(1).

Schomburg, H., \& Teichler, U. (2011). Employability and mobility of bachelor graduates in Europe: Key results of the Bologna Process. Netherlands: Sense Publishers.

Stammen, K. H. (2017). Manual for the conception, planning and realisation of graduate surveys for quality management at higher education institutions. Duisburg/Essen: DuEPublico. doi: http://dx.doi.org/10.17185/duepublico/43571

Teichler, U. (1998). The transition from higher education to employment in Europe. Higher Education in Europe, XXIII(4).

Teichler, U. (1999). Research on the relationships between higher education and the world of work: Past achievements, problems and new challenges. Higher Education, 38: 169-190.

Teichler, U. (2000). Graduate employment and work in selected European countries. European Journal of Education, 35(2).

Teichler, U. (2002). Diversification of higher education and the profile of individual institutions. Higher Education Management and Policy, 14(3).

Teichler, U. (2003). The future of higher education and the future of higher education research. Tertiary Education and Management, 9: 171-185.

Teichler, U. (2011). Lessons to be learned from graduates: Interpretation of the results of graduate surveys. Kassel: INCHER-Kassel UNITRACE.

Wahome, M., Egesah O., \& Wanyama M. (2015). Entrenching quality assurance culture through graduate tracer studies in East Africa: Lessons learnt, challenges and prospects from MUTRACE. International Journal of Education Learning and Development, 3(2); 15-24.

World Bank. (1985). 1985 report on higher education in Sub-Saharan Africa. Discussion Paper. Education and Training Series. Washington: Report No. 3. 